\title{
Analisando a experiência do usuário no stage design brasileiro
}

\section{Analysing the user's experience by brazilian stage design}

\author{
Vitor Almeida ${ }^{[1]}$
}

\begin{abstract}
Resumo: Este artigo se propõe a analisar os fatores que afetam a experiência do público brasileiro ao assistir a um show ao vivo. O cenário atual será analisado em três etapas, por meio de registros, fotos e descrição: (1) shows internacionais no Brasil; (2) a estrutura do entretenimento brasileiro e (3) o comportamento das produtoras nacionais. Com isso, conclui-se que as questões anteriores, aliadas com a geografia e logística presentes nacionalmente, afetam a experiência do usuário em espetáculos apresentados ao público.
\end{abstract}

Palavras-chave: stage design, cenografia, Brasil, experiência.

Abstract: This article aims to analyze the factors affecting the experience of the Brazilian audience when watching a live concert. The current scenario will be analyzed in three stages, through records, photos and description: (1) international concerts in Brazil; (2) the structure of Brazilian entertainment and (3) the behavior of national producers. Thereby, it is concluded that the previous points, allied with the geography and logistics present nation-wide, affects the user experience in concerts presented to the audience.

Keywords: stage design, set design, Brazil, experience. 


\section{INTRODUÇÃO}

O Stage Design (Set Design, Design Cenográfico) é uma parte fundamental da experiência cultural de todos, apesar de muitas vezes não levar crédito e/ou passar despercebida pelo público em geral. A construção de palcos para apresentações e entretenimento da população tem suas raízes iniciais fincadas nos Impérios Gregos. Dois exemplos claros de Stage Design Grego são o Teatro Delphi e o Teatro Epidaurus, ambos construídos em forma cônica que faziam com que o som atingisse até o mais distante assento na plateia.

Atualmente temos grandes espetáculos, que são verdadeiras obras de arte, construídas para a expressão do artista e para a experiência totalmente sensorial do espectador, entretanto, a grande maioria deste tipo de produção audiovisual está localizada no hemisfério norte do globo. Países como Estados Unidos, Canadá e Inglaterra foram berços para a indústria do entretenimento ao vivo. Eventos

Figura 1: Epidaurus Theatre, 300-340 a.C. Fonte: The Ancient Theatre Archive, Whitman College, 2009.

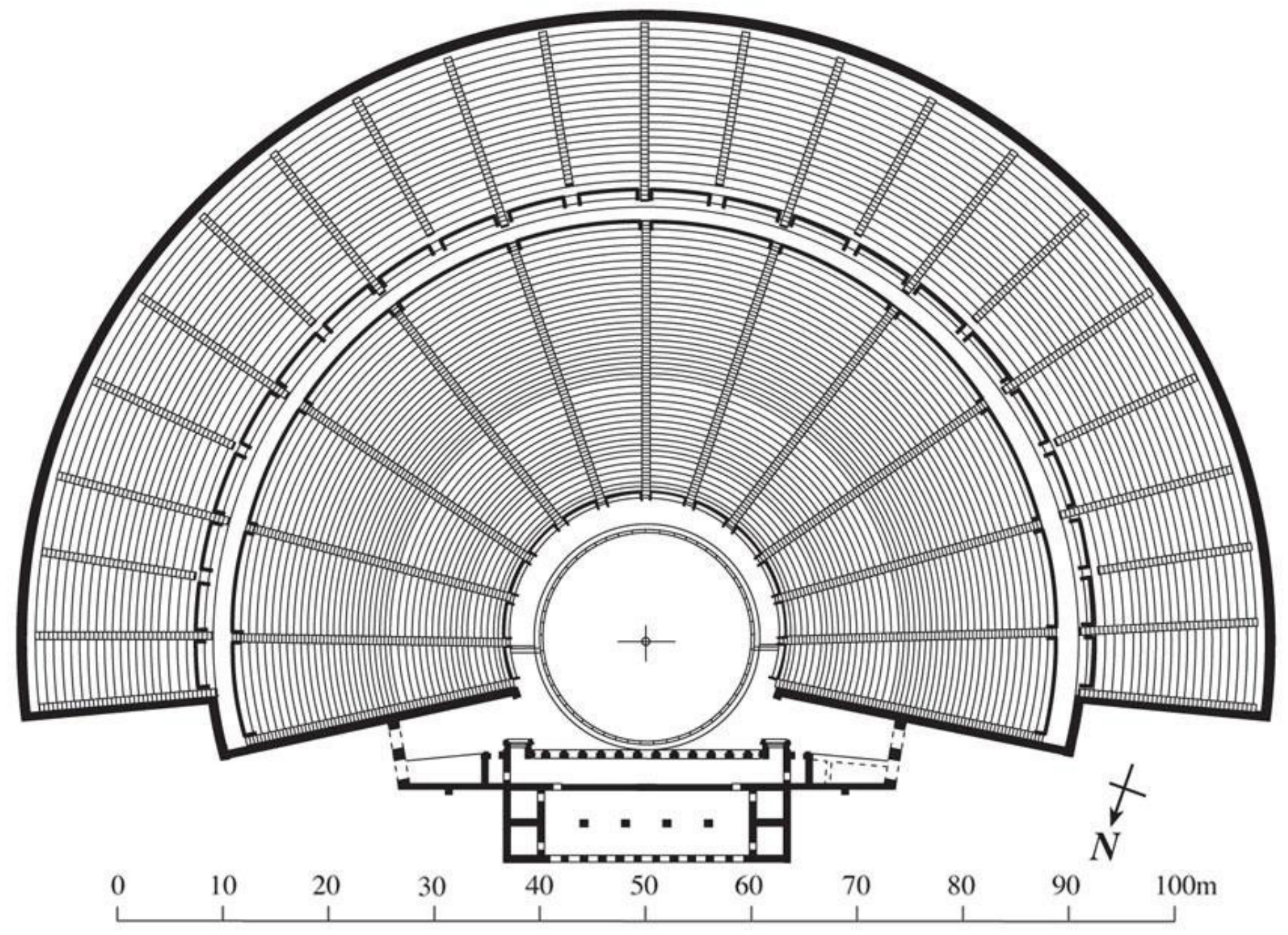


como o Grammy Awards, Super Bowl e o tradicional concurso Eurovision são apenas exemplos de como o Stage Design pode chegar a níveis nunca antes imaginados, sempre acompanhados de muito investimento financeiro e audiências recordes. O show do intervalo da edição 51 do Super Bowl (a final do futebol americano) por exemplo, alcançou $172 \mathrm{mi}-$ Ihões de pessoas mundialmente.

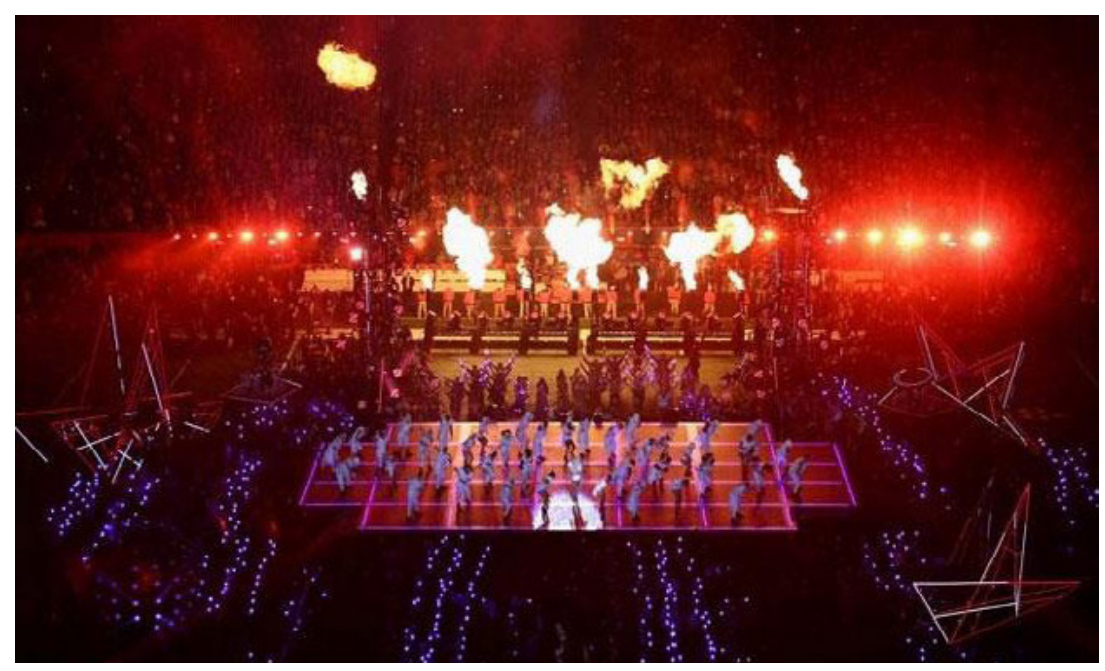

Figura 2: "Super Bowl LI Halftime Show starring Lady Gaga". Fonte: Getty Images, 2017.

No Brasil este cenário é completamente diferente, seja pela falta de estrutura, pela escassez de cursos de graduação públicos na área do Stage Design ou pela ganância das produtoras locais. O que resulta em espetáculos com cenografia e experiência do espectador como um pensamento tardio. Atualmente possuímos poucos cursos de especialização em Cenografia no país, com a maioria localizada no eixo Rio/São Paulo e voltados para a teledramaturgia, devido a demanda das emissoras de televisão que lá se instalam.

Os projetos de cenografia são, em grande maioria, elaborados por profissionais graduados em cursos de Arquitetura e Artes Visuais. Em muitos casos, principalmente em grupos de teatro, as criações cenográficas são realizadas de maneira intuitiva por profissionais do teatro que têm pouco domínio de áreas técnicas e projetuais. (SILVEIRA; ROIZENBRUCH; CORRÊA, 2016, p. 02) 
Neste artigo será mostrada a diferença da realidade nacional e internacional e como a priorização do lucro, ao invés da melhor experiência do público, prejudica o crescimento da indústria cenográfica brasileira.

\section{SHOWS INTERNACIONAIS NO BRASIL}

O Brasil é sempre um destino muito popular entre artistas estrangeiros, shows aqui são certeza de muito dinheiro, segundo a estimativa de estudo da PricewaterhouseCoopers Brasil, o mercado de shows internacionais deve movimentar US $\$ 232$ milhões (aproximadamente R $\$ 900$ milhões) no país. Em 2015, apenas no estado de São Paulo, foram 583 apresentações feitas por artistas que não falam português. A banda britânica The Rolling Stones por exemplo, levou um total de 250 mil pessoas a seus quatro shows no Brasil em 2016.

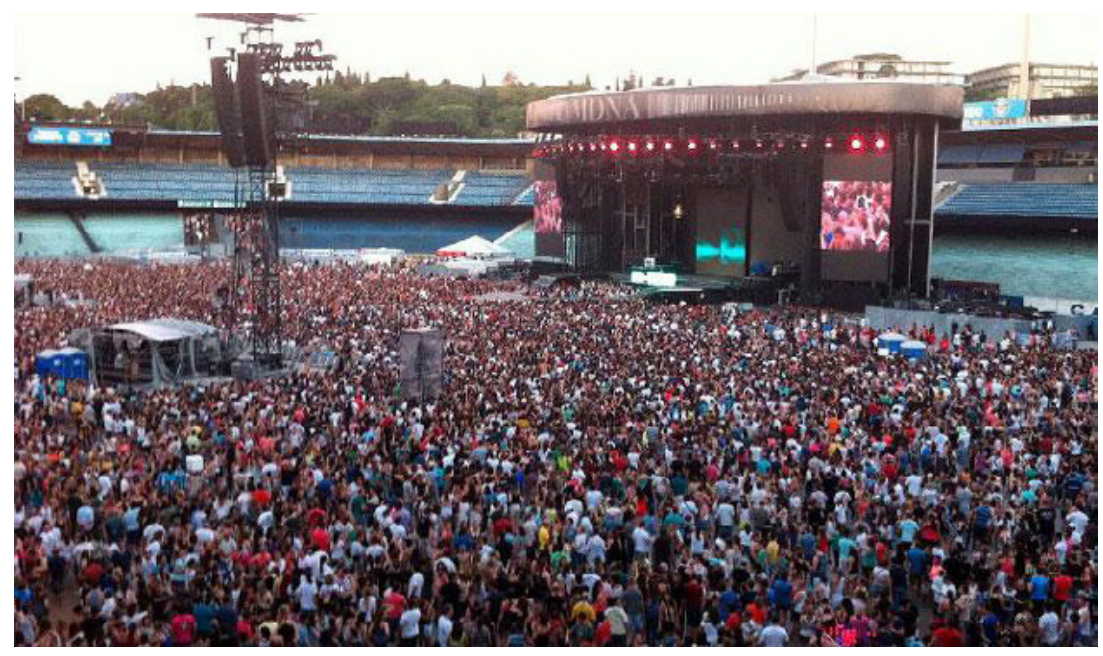

No final de 2012, a cantora norte-americana Madonna trouxe a turnê mundial "The MDNA Tour" para três shows no país: no Rio de Janeiro, em São Paulo e em Porto Alegre. Este caso em específico mostra o quanto a influência da artista pesa na hora da negociação com as produtoras nacionais. Madonna possui uma regra básica para suas turnês: todos terão a mesma experiência. Isso significa que o espectador
Figura 3: Madonna, The MDNA Tour - Estádio Olímpico, Porto Alegre. Fonte: Do autor, 2012. 
que assistiu ao show de estreia em Israel terá a mesma performance que um espectador em Porto Alegre ou no Canadá.

Para os shows de 2012 toda a estrutura cenográfica foi trazida para o país. Sendo este um show concebido para estádios (algo muito comum nas produções que chegam por aqui) todos os prós e contras de se fazer um show em um local tão grande foram levados em conta em sua concepção, minimizando assim, os problemas na experiência do espectador.

Washington DC, USA

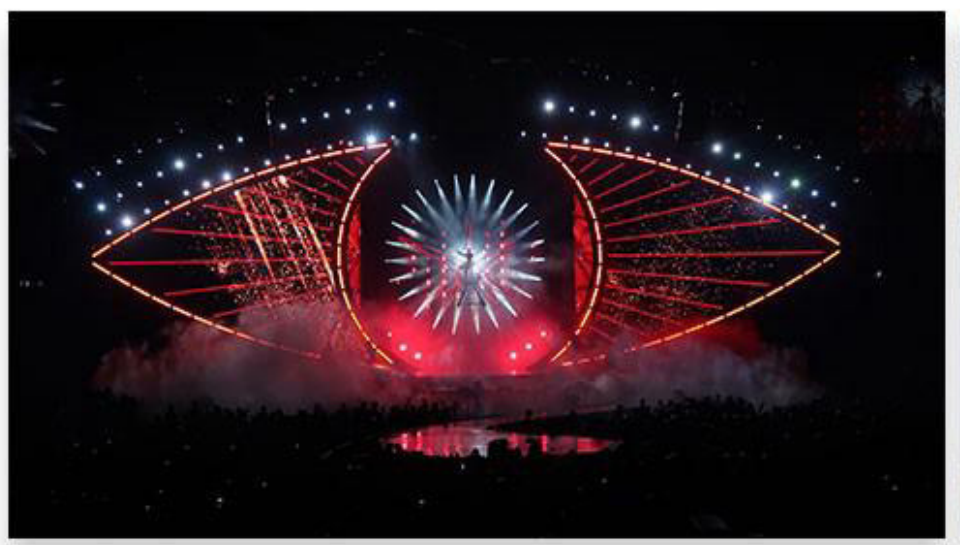

Porto Alegre, BRA

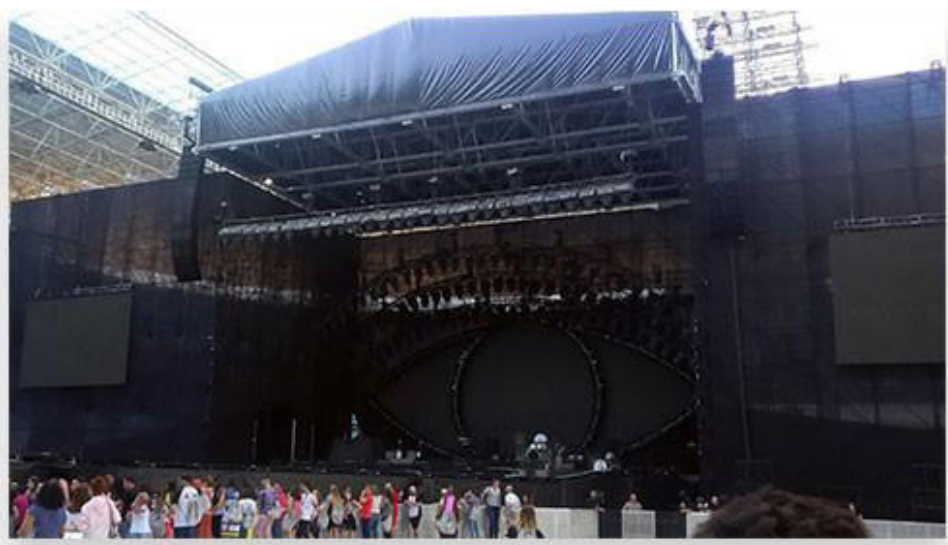

Por outro lado, temos a mais atual turnê de Katy Perry,

Figura 4: Katy Perry, Witness: The Tour. Fonte: Peter Hutchins, 2017 / Do autor, 2018. "Witness: The Tour", que passou pelo Brasil no início de 2018 (pelas mesmas cidades que a veterana Madonna em 2012). Este espetáculo foi concebido para arenas multiuso, espaços fechados para um público de mais ou menos 20 mil pessoas, dessa forma, sua adaptação para estádios faz com a experiência perca muito da fantasia e detalhes técnicos que estavam em sua ideia original. Na montagem de um palco para estádio sempre existe a presença da estrutura que "abriga" o palco em si, essa estrutura não é necessária em arenas o que faz sua inclusão tardia no projeto algo que prejudica desde o ângulo de visão do telão de LED até a iluminação cênica. 
A seguir veremos nas imagens como a simples altura do palco pode influenciar na experiência do espectador.

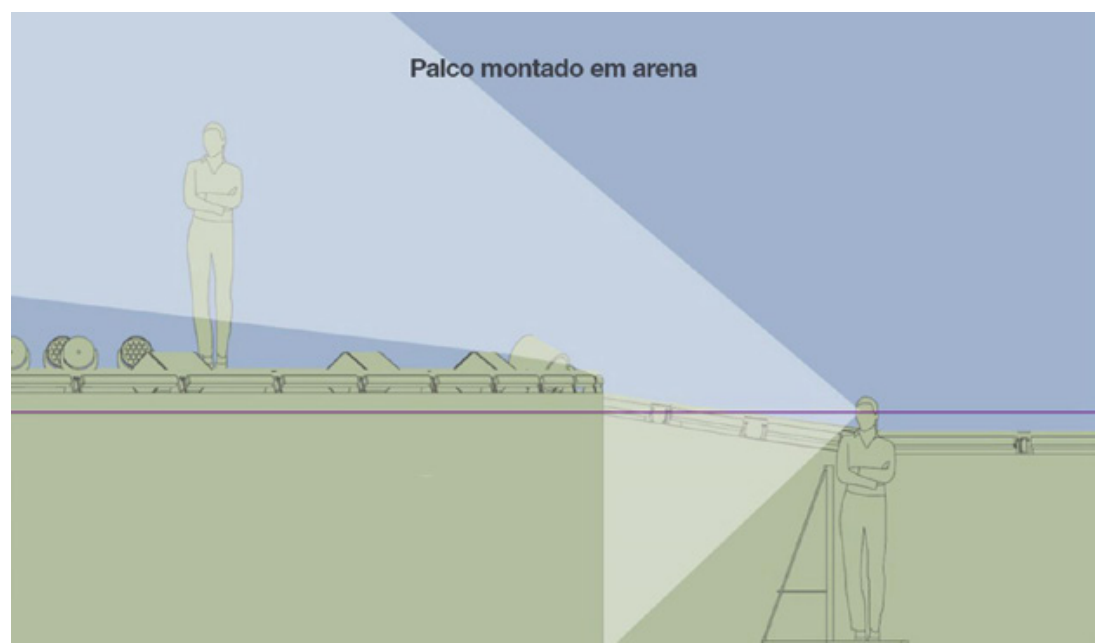

Na Figura 5 (apresentada anteriormente) vemos uma representação gráfica de como seria o ângulo de visão de um espectador na primeira fileira de assentos com a artista posicionada levemente para trás no palco, observamos então que a experiência do usuário não é comprometida neste cenário, inclusive pela distância entre a primeira fileira e a cabeceira do palco não ser excessivamente grande. Já na Figura 6 observamos que quando a altura de um palco originalmente concebido para shows em arenas é alterada, a experiência do usuário é afetada, seu campo de visão diminui significantemente, além da distância entre espectador/artista ser maior.

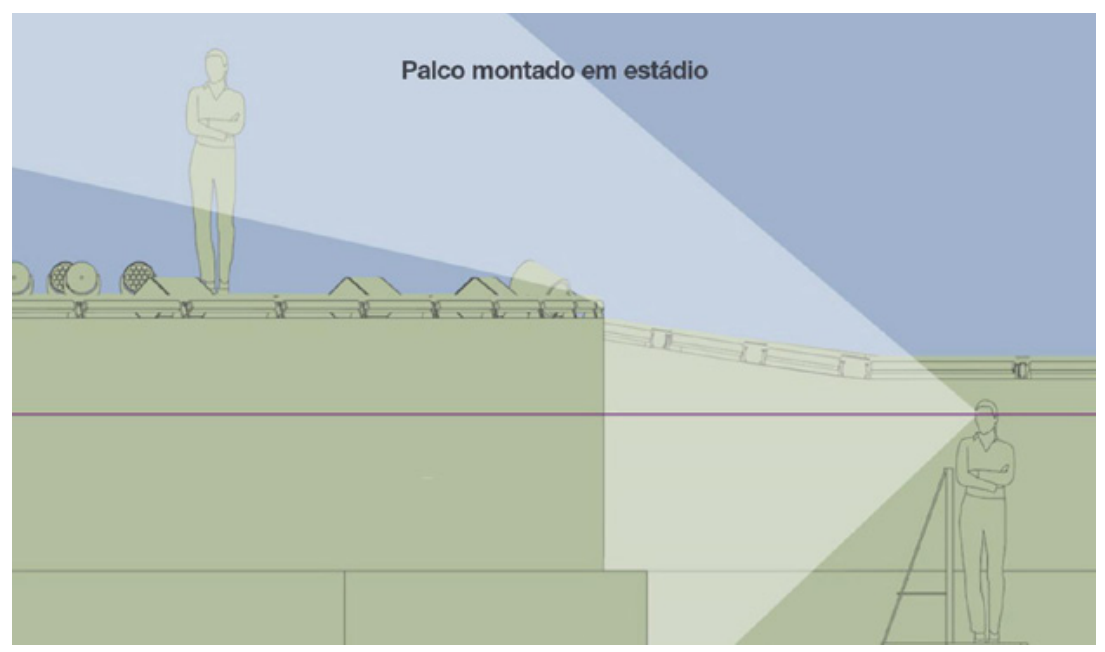

Figura 5: Ilustração da altura de palco em shows dentro de arenas multiuso. Fonte: Do autor, 2019.

Figura 6: Ilustração da altura de palco em shows de estádio. Fonte: Do autor, 2019. 


\section{A ESTRUTURA DO ENTRETENIMENTO BRASILEIRO}

Culturalmente somos o país do futebol e este fato toma a frente dos maiores problemas do Brasil quando o assunto é entretenimento. Arenas multiuso, disponíveis abundantemente na América do Norte e Europa, são restringidas no Brasil a três locais, todos localizados dentro do Parque Olímpico no Rio de Janeiro, o que dificulta a logística na hora de contratar shows internacionais. A variedade de lugares em que o artista se apresenta está atrelada ao sucesso de vendas, portanto três datas no mesmo local apenas se sustentam com demanda altíssima de ingressos, algo difícil na realidade econômica brasileira.

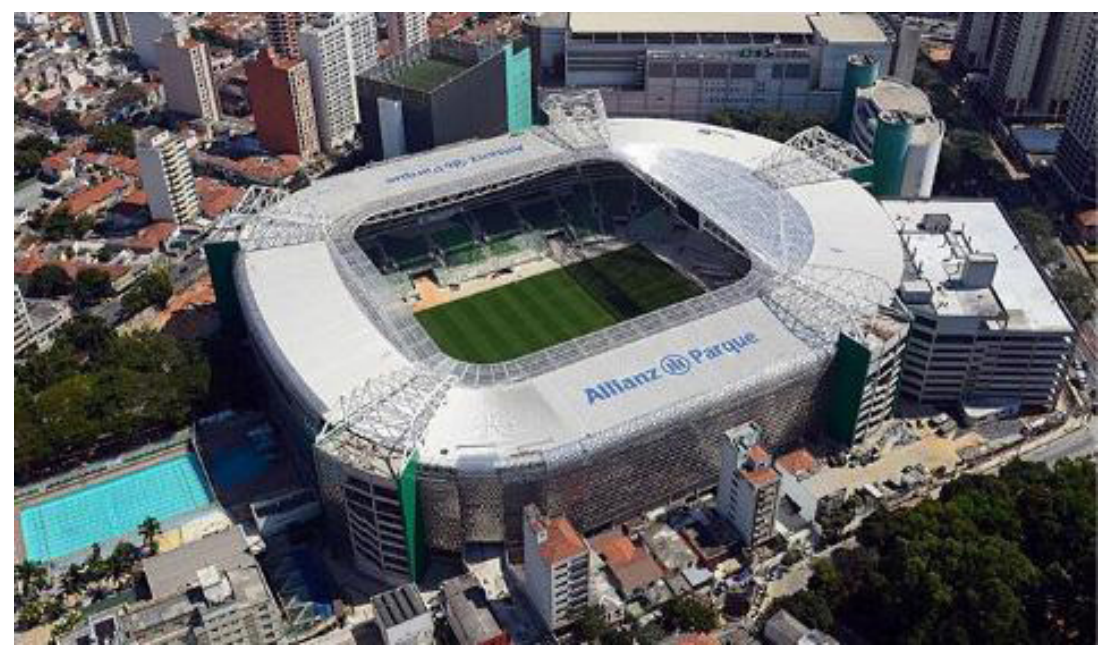

Com a chegada da Copa do Mundo de 2014 tivemos vários estádios construídos utilizando tecnologia de ponta, porém, estádios gigantes foram projetados em sua maioria para uma função: futebol. O calcanhar de Aquiles do Brasil é sua falta de diversidade esportiva. Depender exclusivamente do futebol é uma realidade que não ajuda a fomentar a indústria do entretenimento.

Em outros países do hemisfério norte vemos várias configurações para as chamadas arenas multiuso, cada uma delas pode servir para acomodar confortavelmente um público em média de 15 mil pessoas, para jogos de basquete, hóquei no
Figura 7: Allianz Parque - São Paulo. Fonte: Thiago Fatichi, 2014. 
gelo, eventos empresariais e concertos. Esta é a vantagem que viabiliza um empreendimento deste porte, seu uso múltiplo o torna economicamente rentável. No Brasil os estádios construídos para a Copa do Mundo, em sua maioria, só se pagam com partidas de futebol e shows de estádio.

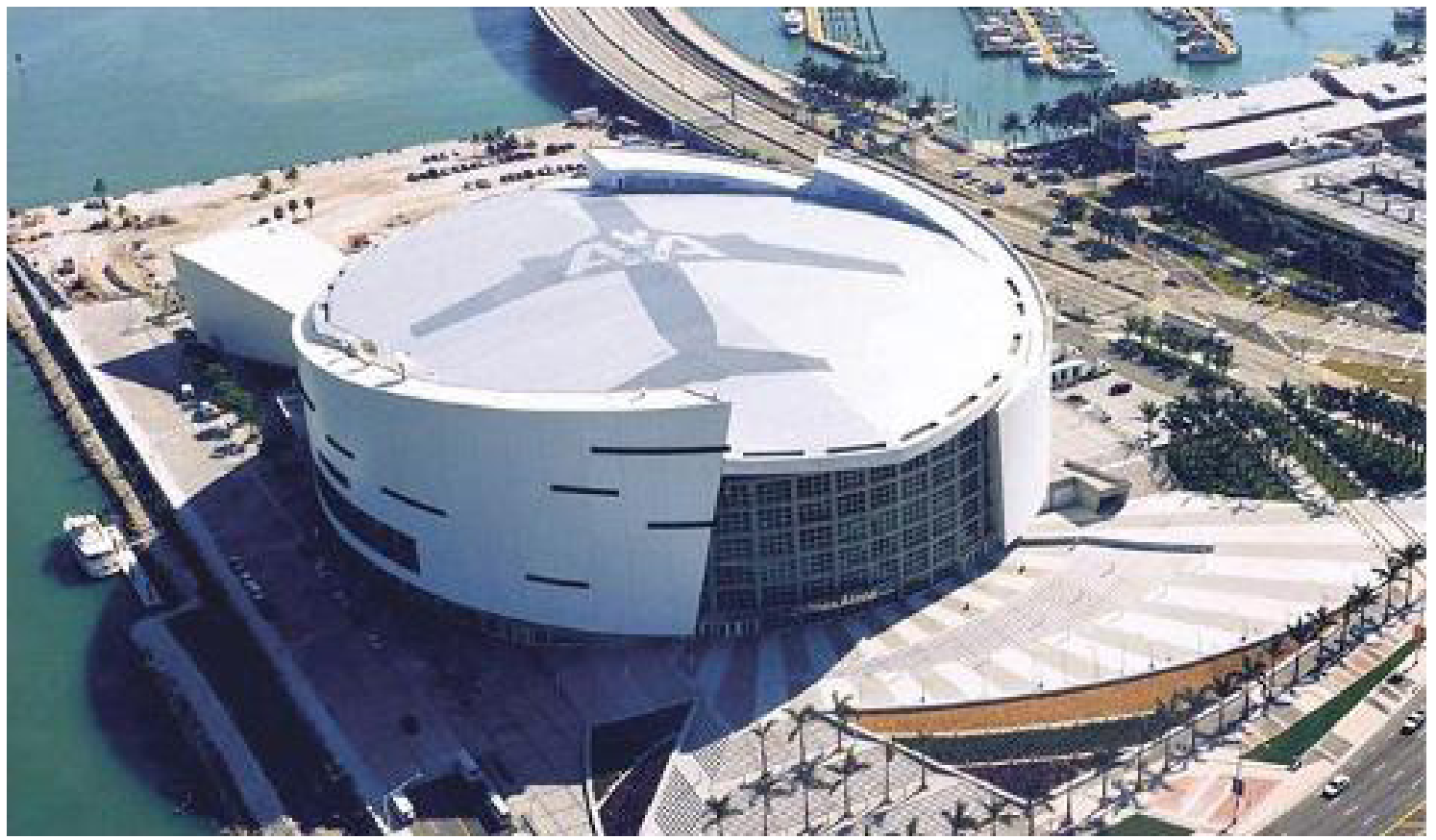

A falta de estrutura não atinge apenas artistas internacionais, artistas brasileiros também sofrem para transmitir sua visão para o público. Ivete Sangalo é uma cantora baiana que está sempre em turnê, entretanto não é possível rodar o Brasil com o mesmo palco devido às limitações estruturais de cada casa de show. Artistas brasileiros estipulam cachês dependendo de quanto investimento o contratante do show está disposto a investir, quanto maior o valor, mais estrutura e parafernália visual ele leva. Atualmente, artistas nacionais precisam se contentar em apresentar sua expressão artística da maneira que é possível, algo quase impensável para artistas internacionais.
Figura 8: American Airlines Arena - Miami. Fonte: Langan Architects, 2008. 


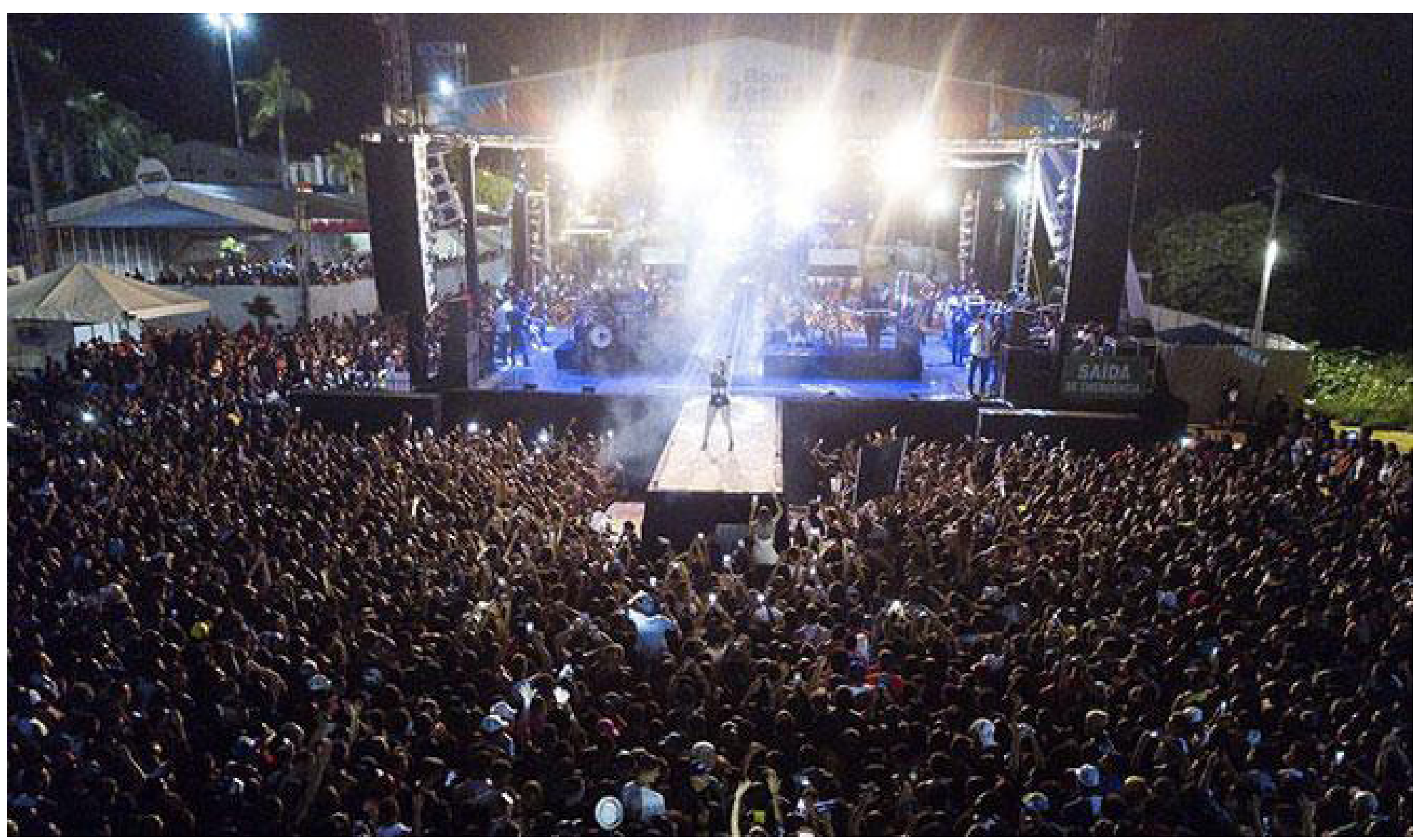

\section{O COMPORTAMENTO DAS PRODUTORAS NACIONAIS}

Pela falta de estrutura e por ter dimensões continentais, o Brasil sofre por perder espetáculos incríveis pelo simples custo altíssimo de transporte. Para amenizar esta situação as produtoras brasileiras se acostumaram a sempre pagar o cachê mais barato para o artista e a forçar a lotação do local, isto se traduz em frustração e desconforto para os fãs. Atualmente o Brasil não possui leis para padronização de assentos em concertos, legislando apenas para locais com capacidade de até 1.000 pessoas e com dificuldade de locomoção, segundo o Decreto N 9.404 deixa claro que: “...para dispor sobre a reserva de espaços e assentos em teatros, cinemas, auditórios, estádios, ginásios de esporte, locais de espetáculos e de conferências e similares para pessoas com deficiência..." (BRASIL, 2018). Isso permite que a lotação máxima de um local seja sempre com o público em pé o que se traduz em mais pessoas por metro quadrado, maximizando o lucro por ingresso individual.
Figura 9: Anitta em Penedo, RJ. Fonte: Rodamoinho Produções, 2018. 


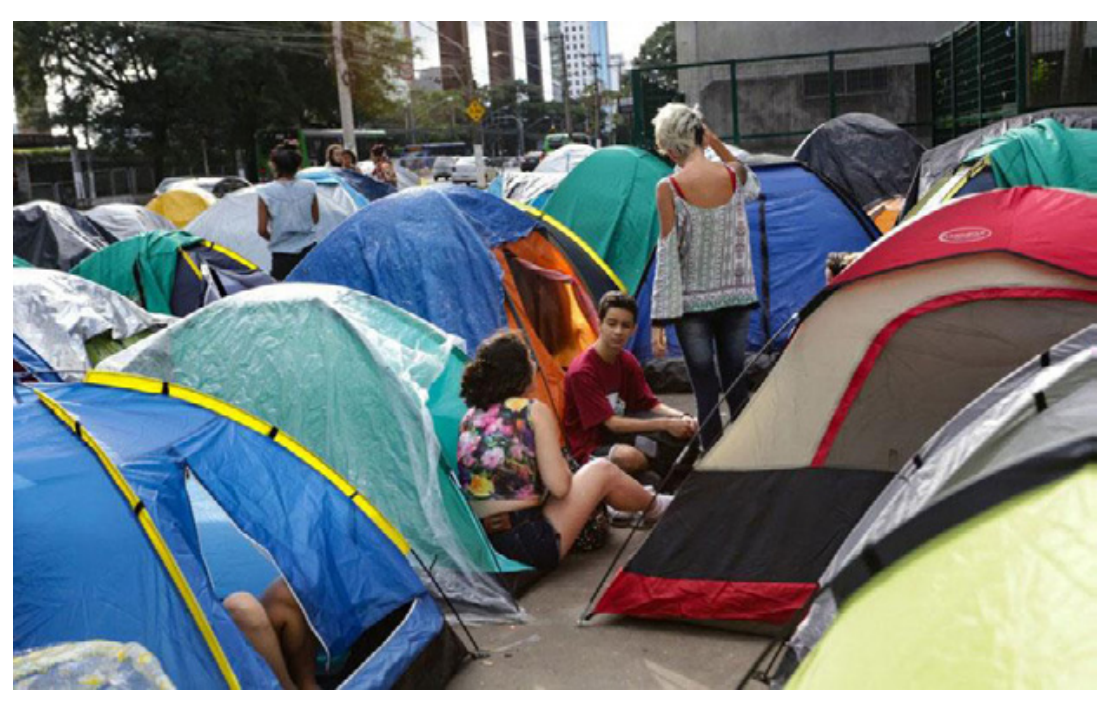

Alguns promotores utilizam a 'meia-entrada universal' e promovem lotes promocionais pela metade para os primeiros consumidores. Ou oferecem $50 \%$ de desconto para clientes de empresas e bancos. A meia-entrada virou uma propriedade comercial. E o que eles fazem para conseguir mais lucro? Dobram nominalmente o preço do ingresso. (MARTINELLI, apud BELLONI, 2017)
Figura 10: Fãs acampam por meses para show de Justin Bieber - São Paulo. Fonte: Estadão, 2017.

Além disso a lei da meia entrada prejudica a todos, as produtoras utilizam a mesma como uma desculpa para aumentar os preços dos ingressos normais para assim, não disponibilizar ingressos de meia entrada muito baratos.

\section{CONSIDERAÇÕES FINAIS}

Como vimos, o Stage Design está presente em nossa cultura muitas vezes sem o devido destaque. Com origem grega, mantém vários aspectos originais (por exemplo os teatros em forma cônica) até hoje. Atualmente a indústria do entretenimento ao vivo é muito forte na América do Norte, Europa, Ásia e até Oceania. Grandes premiações e eventos televisivos investem alto em cenografia para continuarem relevantes. Entretanto no Brasil a realidade é oposta: a área de estudo é limitada, o espectador não é posto em primeiro lugar e a estrutura é deficiente. 
Nosso país é destino certo na hora de receber grandes artistas. Porém a experiência do espectador nem sempre é igual a de outros países. Alguns artistas tem o poder de barganha para negociar e trazer seu show completo para cá, o que acaba dificultando para outros mais novos. Com nossa abundância de estádios de futebol e escassez de arenas multiuso acabamos sendo forçados a adaptar espetáculos, algo que sempre prejudica algum aspecto do show.

Pelo tamanho continental do Brasil, os problemas de logística se acumulam, forçand o a maioria dos artistas a estarem sempre nas mesmas cidades. Além disso, as produtoras locais focam em lucro e escolhem esquecer a experiência dos fãs.
Figura 11: Bumbódromo de Parintins - Amazonas. Fonte: Ícaro Guimarães, 2018.

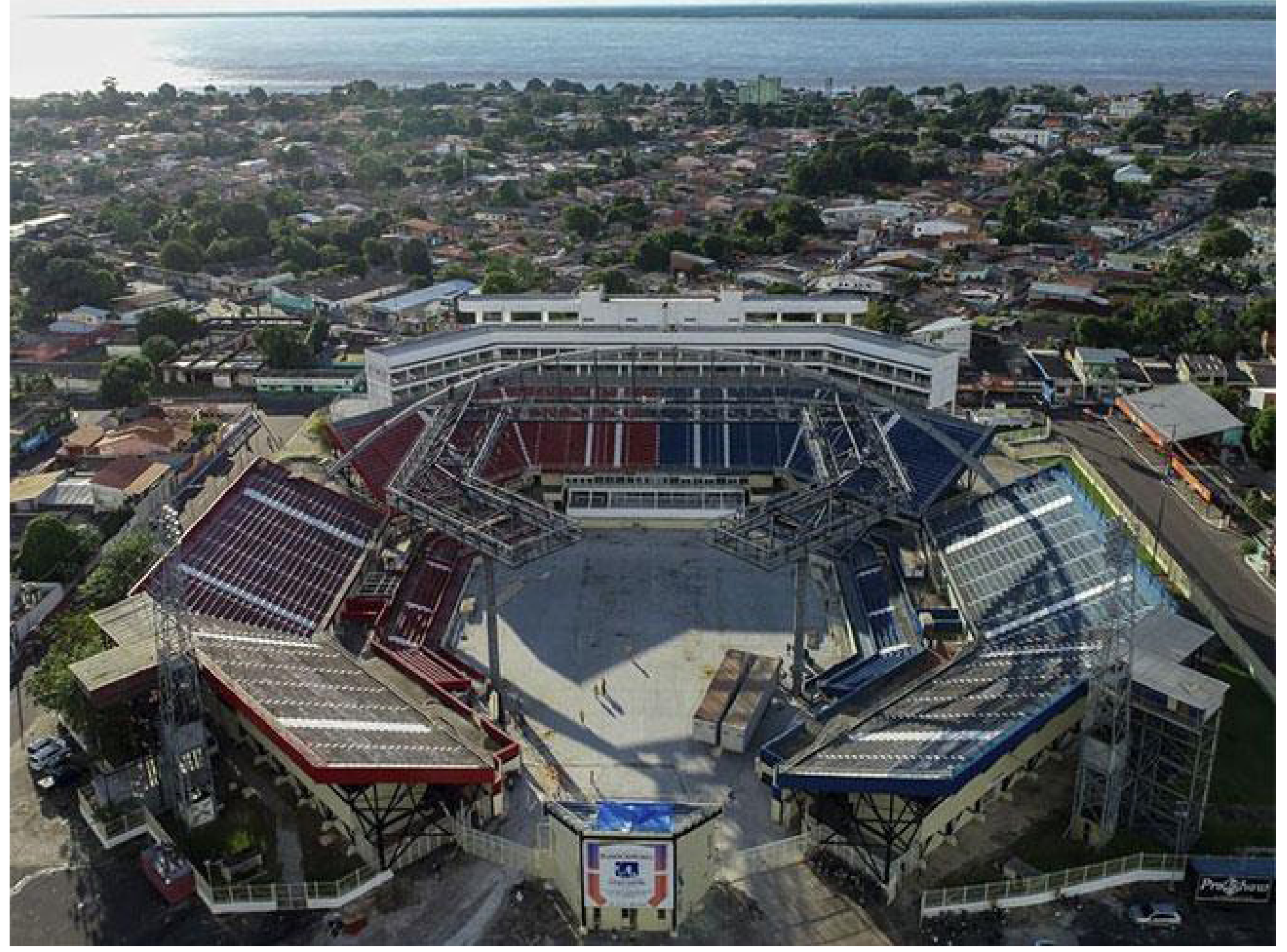


Por fim, percebemos que o conjunto de desvantagens enfrentadas pelo mercado brasileiro se transforma numa verdadeira bola de neve quando juntamos a inércia empresarial com arcabouço tributário.

O Brasil é cenário de grandes eventos, do Carnaval Carioca ao Festival Folclórico de Parintins, e possui mão de obra extremamente qualificada para criar espetáculos dignos de títulos internacionais, entretanto, a ganância e o descaso com o público brasileiro fazem com que o cenário atual seja digno de frustração. Temos falhas no momento de abrigar grandes shows internacionais em verdadeiros templos do esporte nacional como o Maracanã, temos falta de estrutura na hora de criar um concerto para grandes artistas do Axé, Pop e Funk e temos condutas questionáveis de produtoras locais que visam o lucro máximo sem olhar a quem. Este não é um problema fácil de ser resolvido, porém necessita de atenção e um olhar mais aprofundado para as expectativas do público brasileiro se igualarem com a demanda internacional.

\section{REFERÊNCIAS BIBLIOGRÁFICAS}

44 ARQUITETURA. Arquitetura cenográfica: já pensou em trabalhar com ela?. Disponível em: <http://44arquitetura. com.br/2017/07/arquitetura-cenografica-trabalhar -com-ela/>. Acesso em: 31 de jan. 2019.

BELLONI, Luiza. A 'ilusão' da meia-entrada: Este é o motivo pelo qual voce $\square$ não paga a metade do preço de um ingresso. Disponível em: <https://www.huffpostbrasil.com/2017/08/04/a-ilusaoda-meia-entrada-este-e-o- motivo-pelo-qual-vocenao-p_a_23063706/>. Acesso em: 01 de jul. 2018.

BRASIL. Decreto n 9.404, de 11 de junho de 2018.

Dispõe sobre a reserva de espaços e assentos em teatros, cinemas, auditórios, estádios, ginásios de esporte, locais de espetáculos e de conferências e similares para pessoas 
com deficiência. Disponível em: <http://www.in.gov.

br/materia/-/asset_publisher/Kujrw0TZC2Mb/content/ id/25211987/do1-2018-06-12-decreto-n-9-404-de-11-dejunho-de-2018-25211887/>. Acesso em: 31 out. 2019.

HINES, Thomas G. The Ancient Theatre Archive:

Epidaurus Theatre. Disponível em: <https://www. whitman.edu/theatre/theatretour/epidaurus/ epidaurus.htm>. Acesso em: 17 de set. 2019.

IRWIN, Janet. Scenic Design: A History of Change and Innovation. Disponível em: <http://www.artsalive.ca/ collections/imaginedspaces/index.php/en/learn- about/ historyandinnovation>. Acesso em: 30 de jun. 2018.

KNOPPER, Steve. How concerts shifted from songs to spectacles. Disponível em: <https://www.washingtonpost. com/entertainment/music/how- concerts-shifted-fromsongs-to-spectacles/2014/05/22/ca521340-d6ce-11e3-8a788fe50322a72c_story.html>. Acesso em: 01 de jul. 2018.

LUCIANI, N. Design cênico: um caminho possível para a criação da luz e a formação do iluminador. Florianópolis, 2013.

MIX MAG BRASIL. Mercado de shows deve movimentar US\$232 milhões em 2016. Disponível em: <http://mixmag. com.br/read/mercado-de-shows-deve- movimentar-us232-milhoes-em-2016-news>. Acesso em: 30 de jun. 2018.

SILVEIRA, Y.; ROIZENBRUCH, T.; CORRÊA, L. Design cenográfico: cenografia como habilitação nos cursos de design. Belo Horizonte, 2016.

WILD, Larry. A Brief History of Theatrical Scenery. Disponível em: <http://www3.northern.edu/wild/ ScDes/sdhist.htm>. Acesso em: 30 de jun. 2018. 
ZIRPOLI, Cassio. A audiência do Super Bowl na TV

dos EUA, há 8 anos com mais

de 100 milhões de telespectadores. Disponível em: <http://

blogs.diariodepernambuco.com.br/esportes/2017/02/06/

a-audiencia-do-super- bowl-na-televisao-ha-8-anos-

com-mais-de-100-milhoes-de-telespectadores-

segue- atras-da-copa/>. Acesso em: 01 de jul. 2018. 